\title{
NILAI-NILAI PENDIDIKAN ISLAM DALAM RITUAL ADAT POSALAMA POGUNCI BULUA PADA ETNIS KAILI DI KELURAHAN PETOBO KOTA PALU
}

\author{
Hamlan Andi Baso Malla \\ Institut Agama Islam Negeri Palu \\ E-mail: hamlan@iainpalu.ac.id
}

\section{Ardillah Abu}

Institut Agama Islam Negeri Palu

E-mail: ardillah_abu@iainpalu.ac.id

\section{Husni Mubarak \\ Institut Agama Islam Negeri Palu \\ E-mail: husnimubarak@gmail.com}

\begin{tabular}{|c|c|c|}
\hline Received & Revised & Accepted \\
\hline 10 Januari 2021 & 10 Februari 2021 & 28 Maret 2021 \\
\hline
\end{tabular}

\section{VALUES OF ISLAMIC EDUCATION IN TRADITION RITUAL OF POSALAMA PAGUNCI BULUA TO KAILI ETCHNIC AT KELURAHAN PETOBO IN PALU}

\begin{abstract}
This study aims to determine the values of Islamic education contained in the Posalama Pogunci Bulua Traditional Ritual of the Kaili Ethnic in Petobo Village, South Palu District. In this study, the author uses a type of qualitative descriptive research, which describes practically the object under study. Based on these data, the results of this study reveal that: (1) The process of implementing the traditional ritual of Posalama Pogunci Bulua on the Kaili ethnic group in the Petobo Village has several stages that must be carried out including the pokeso custom, preparing the materials used when the traditional ritual is carried out. and aqikah events. In carrying out these traditional rituals they still use the traditions inherited by their ancestors, namely by using symbols such as coconut, rice, candles, siranindi leaves, eggs, and money. These symbols have their own meanings. (2) For the Kaili ethnic community in Petobo Village, the traditional ritual of Posalama Pogunci Bulua is a form of gratitude to Allah SWT. for the children entrusted to them and also as a place of friendship between family and neighbors. While the meanings contained in the symbols used are not as material to be worshiped but as a prayer and hope for both parents to the child that they pray to Allah SWT. (3) In the review of Islamic education, the traditional ritual of posalama pogunci Bulua contains educational values including the value of faith education, the value of moral education, and the value of social education.
\end{abstract}

Keywords: Islamic education values, traditional rituals, and posalama pogunci bulua. 


\begin{abstract}
Abstrak
Penelitian ini bertujuan untuk mengetahui nilai-nilai Pendidikan islam yang terkandung dalam Ritual Adat Posalama Pogunci Bulua pada Etnis Kaili di Kelurahan Petobo Kecamatan Palu Selatan. Dalam penelitian ini, penulis menggunakan jenis penelitian deskriptif kualitatif, yakni memaparkan secara praktis tentang objek yang diteliti. Berdasarkan data tersebut maka hasil penelitian ini mengungkapkan bahwa : (1) Proses pelaksanaan ritual adat posalama pogunci bulua pada etnis Kaili di Kelurahan Petobo memiliki beberapa tahapan-tahapan yang harus dilaksanakan diantaranya yaitu adat pokeso, menyiapkan bahan-bahan yang digunakan pada saat ritual adat dilaksanakan dan acara akikah. Dalam pelaksanaan ritual adat ini mereka masih menggunakan tradisi-tradisi yang diwarisi oleh leluhur mereka yaitu dengan menggunakan simbol-simbol seperti kelapa, beras, lilin, daun siranindi, telur dan uang. Simbol-simbol tersebut memiliki makna-makna tersendiri. (2) Bagi masyarakat etnis Kaili di Kelurahan Petobo bahwa ritual adat posalama pogunci bulua ini adalah salah satu bentuk rasa syukur kepada Allah Swt. atas anak yang dititipkan kepada mereka dan juga sebagai tempat silaturahim antar keluarga dan tetangga. Sedangkan makna yang terkandung pada simbol-simbol yang digunakan bukanlah sebagai bahan untuk disembah melainkan sebagai do'a dan harapan kedua orang tua kepada anak tersebut yang mereka panjatkan kepada Allah Swt. (3) Dalam tinjauan pendidikan Islam, ritual adat posalama pogunci bulua ini mengandung nilai-nilai pendidikan diantaranya yaitu nilai pendidikan keimanan, nilai pendidikan akhlak dan nilai pendidikan sosial.
\end{abstract}

Kata kunci: nilai-nilai pendidikan islam, ritual adat, dan posalama pogunci bulua.

\title{
Pendahuluan
}

Masyarakat Indonesia adalah masyarakat yang majemuk, salah satu akibat dari kemajemukan tersebut adalah terdapat beraneka ragam Ritual Adat Keagamaan yang dilaksanakan dan dilestarikan oleh masing-masing pendukungnya. Ritual Adat Keagamaan tersebut mempunyai bentuk atau cara melestarikan serta maksud dan tujuan yang berbeda-beda antara kelompok masyarakat yang satu dengan masyarakat yang lainnya. Hal ini disebabkan oleh adanya perbedaan lingkungan tempat tinggal, adat serta tradisi yang diwariskan secara turun temurun. ${ }^{1}$

Dimana kegiatan tersebut terus eksis dimasyarakat sebagai pelestarikan adat dan istiadat budaya leluhur. Indonesia merupakan Negara yang kaya akan budaya dan ritual-ritual, disetiap daerah yang ada di negeri ini memiliki ritual yang berbedabeda seperti keyakinannya, pelaksanaannya, dan makna-maknanya.

Demikian halnya dengan ritual adat Posalama Pogunci Bulua dilaksanakan bersamaan dengan pelaksanaan Akikah sebagi bentuk alkulturasi antara syariat islam dengan ritual adat sebagian masyarakat kaili khusunya di kelurahan petobo pada prosesi akikah. Ritual adat serupa dapat ditemukan diberbagai tradisi misalnya di Kabupaten Gowa misalnya, tradisi Akcaru-caru dilaksanakan bersamaan dengan pelaksanaan Akikah. Tradisi Akcaru-

Hamlan, Ardillah Abu dan Husni Mubarak,

NILAI-NILAI

${ }^{1}$ Imran Arbi Pogogul dan Orang Buol (Mitos Kepercayaan Orang Buol terhadap Kesakralan Gunung Pogogul di Desa Taluan Kecamatan Momunu Kabupaten Buol. 2006): 2. 
caru ini biasa dilakukan oleh masyarakat Desa Salajangki sebagai bentuk rasa syukur atas anak anak yang baru dilahirkan. Masyarakat Desa Salajangki Mempercayai tradisi ini sebagai bentuk terima kasih kepada Allah Swt atas kelahiran anak mereka. Tradisi Akcaru-caru ini merupakan ritual turun-temurun yang telah di wariskan oleh nenek moyang sejak lama. Prosesi akcaru-caru ini dilakukan dengan beberapa tahapan yaitu nisimba, nisingkolo, dan aktompolok setelah prosesi akcaru-caru selesai kemudian keluarga membawa ja’jakan berupa beras dan sejumlah uang sesuai dengan keikhlasan orang tua anak kerumah sandro pamana. ${ }^{2}$

Tradisi yang serupa juga dilaksanakan pada masyarakat muslim Gorontalo, gunting rambut anak dinamakan mohuntingo. Sedangkan pemberian nama kepada anak dinamakan mongunte. Sementara penyembelihan hewan dimaknai secara spesifik dengan istilah mongakiki atau melaksanakan akikah. Yang menarik dicermati dalam konteks tradisi mongakiki bagi muslim Gorontalo adalah perlakuan terhadap kambing yang akan disembelih. Bahwa sebelum kambing akikah disembelih terlebih dahulu tubuh dan lehernya diolesi dengan yilonta (minyak harum dari ramuan), dan dikalungi emas atau mutiara, serta dibaluti kain putih. Secara kultural, polesan yilonta sebagai simbol atas ketulusan hewan akikah. Sementara kain putih menunjukkan kesucian hati pelaksana akikah. Sedangkan secara filosofis, perlakuan terhadap hewan akikah menunjukkan kesungguhan diri dalam mengekspresikan kesyukuran terhadap anugrah Tuhan. Ritual adat mongakiki dalam tradisi Gorontalo merupakan ekspresi jiwa yang tulus dan sungguh-sungguh untuk mempersembahkan kebaktiannya kepada Tuhan secara maksimal. ${ }^{3}$

Masyarakat Petobo meyakini bahwa pelaksanaan Posalama Pogunci Bulua sebagai bentuk rasa syukur kepada Allah Swt. atas kelahiran anak, selain itu ritual adat ini sebagai wadah silaturahmi antara pihak keluarga dengan tetangga, sanak saudara maupun kerabat yang jauh dengan tujuan menjalin keakraban dalam bingkai kekeluargaan.

Untuk itu, tulisan ini betujuan untuk mengetahui pelaksanaan, makna-makna yang terkandung pada Ritual Adat Posalama Pogunci Bulua dalam rangkaian prosesi akikah masyarakat etnis kaili ditinjau dari nilai-nilai Pendidikan islam.

\section{Metode Penelitian}

Penulis menggunakan jenis penelitian deskriptif kualitatif, yakni memaparkan secara praktis tentang objek yang diteliti. Penelitian kualitatif menurut Sugiyono "digunakan untuk menggunakan data yang mendalam, sesuatu data yang mengandung makna. Makna adalah data yang sebenarnya, data yang pasti merupakan suatu nilai di balik data yang tepat dalam penelitian". ${ }^{4}$ Jurnal Paedagogia Vol. 10 No. 1 Maret 2021

\footnotetext{
${ }^{2}$ Henri, Tradisi Akcaru-caru dalam pelaksanaan di Desa Sala'jangki Kecamatan Bontonompo Selatan Kabupaten Gowa (Studi Dakwah Kultural) Skripsi diterbitkan (Makassar : Jurusan Komunikasi dan Penyiaran Islam, UIN Alauddin): 3-5.

${ }^{3}$ Sofyan A.P. Kau Islam dan Budaya Lokal Adat Gorontalo (makna filosofis, Normatif, Edukatif dan Gender (Malang : PT Cita Intrans Selaras, 2020): 111-112

${ }^{4}$ Sugiyono, Metode Penelitian Pendidikan Pendekatan Kuantitatif, Kualitatif dan R\&D, (Bandung: Alfabet, 2010): 15.
} 
Seluruh data yang dikumpulkan akan diolah dan diseleksi berdasarkan menggunakan penelitian kualitatif yang menitik beratkan kepada kegiatan penelitian di lokasi objek dalam melakukan penelitian yang ada, dengan tujuan memperoleh data ilmiah yang bersifat alamiah dan tidak menimbulkan hipotesis yang sifatnya menduga-duga berbagai hal yang menyangkut tentang proses Ritual Adat Posalama Pogunci Bulua Pada Etnis Kaili di Kelurahan Petobo Kecamatan Palu Selatan. Kehadiran peneliti mutlak adanya sebagai upaya untuk mendapatkan dan mengumpulkan data. kedudukan peneliti merupakan perencana, instrumen utama, pengumpul data, penganalisis data sampai pada akhirnya peneliti melaporkan hasil penelitian.

Dalam pengumpulan data, penulis menerapkan tiga macam tekhnik pengumpulan data yaitu wawancara, observasi dan dokumentasi. Pengecekan keabsahan penulis menggunakan triangulasi dimana hasil dokumentasi mulai dari penyiapan bahan-bahan, dan tahapan-tahapan ritual posalama pagunci bulua, rangkaian ritual tersebut semuanya dicek dan dikomparasikan dengan hasil wawancara dan dokumentasi. Metode ini digunakan untuk mengetahui makna dibalik Ritual Adat Posalama Pogunci Bulua dalam rangkaian prosesi akikah masyarakat etnis kaili ditinjau dari nilai-nilai Pendidikan islam.

\section{Hasil dan Pembahasan \\ Prosesi Pelaksanaan dan makna Ritual Adat Posalama Pogunci Bulua Pada Etnis Kaili di Kelurahan Petobo.}

Ritual adat posalama pogunci bulua ini dilaksanakan secara turun temurun dari leluhur masyarakat etnis kaili di kelurahan petobo, sebagai bentuk rasa syukur dikaruniai seorang anak. Ritual adat posalama pogunci bulua bagi etnis kaili adalah salah satu rangkaian yang tidak bisa dilepaskan dari prosesi akikah. Menurut Ketua Adat Kelurahan Petobo bahwa “Adat Posalama Pogunci Bulua ini adalah suatu ritual adat yang dilaksanakan dalam rangkaian pelaksanaan akikah dari kelahiran anak dan akikah merupakan sunnah Nabi Muhammad Saw". ${ }^{5}$

Ritual Adat Posalama Pogunci Bulua pada Etnis Kaili di Kelurahan Petobo terdapat beberapa proses pelaksanaannya, yaitu seperti yang dikatakan oleh Dewan Syuro Kelurahan Petobo.

"Sebelum pelaksanaan prosesi akikah, yang dilakukan pertama kali yaitu adat pokeso yaitu si anak yang akan di akikah harus dibersihkan atau disucikan dengan air wudhu, kemudian keluarga menyiapkan beberapa bahan-bahan pelengkap untuk pelaksanaan adat posalama pogunci bulua dan yang terakhir yaitu prosesi akikah (menggunting rambut)."

${ }^{5}$ Halati Yabudjira. Ketua Adat Kelurahan Petobo, Wawancara oleh penulis dirumah Ketua Adat. 26 Januari 2021.

${ }^{6}$ Suardin Ilyas. Dewan Syuro Kelurahan Petobo. Wawancara oleh penulis dirumah. 27 Januari 2021. 


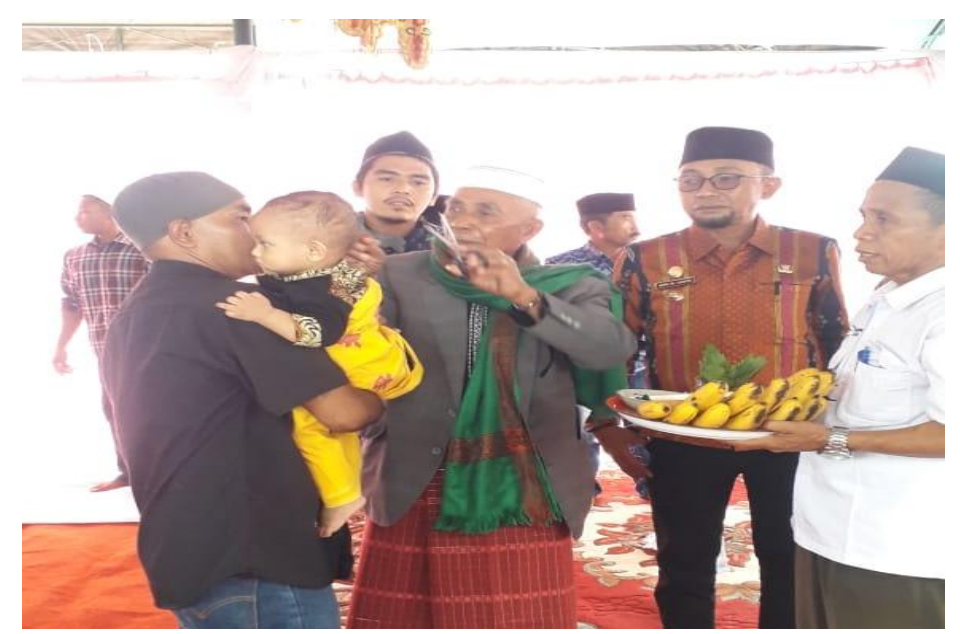

Gambar 1. Prosesi Ritual Posalama Posalama Pogunci Bulua dalam rangkaian akikah

Bahan yang dipersiapkan untuk pelaksanaan ritual adat posalama pogunci bulua mempunyai makna-makna tersendiri yang utamanya adalah untuk kesehatan, keselamatan dan juga menyangkut kepribadian anak tersebut. Ritual adat posalama pogunci bulua terdapat beberapa tahapan pelaksanaan yaitu, pertama adalah tahapan Adat pokeso artinya adalah dibersihkan atau disucikan dengan air wudhu terlebih dahulu kepada anak sebelum dilaksanakan akikah. ${ }^{7}$ Tahapan kedua Mempersiapkan bahan-bahan untuk ritual adat posalama pogunci bulua. Dalam pelaksanaan ritual adat posalama pogunci bulua terdapat beberapa bahanbahan penunjang yang harus disiapkan diantaranya yaitu Tovau (kambing), jaka ialah sebuah mangkuk kecil dan loja ialah sebuah talang kecil. Tahapan ketiga Prosesi pogunci bulua (gunting rambut) Pada pelaksanaan prosesi akikah di Kelurahan Petobo khusunya etnis Kaili terdapat tiga susunan acara yang harus diperhatikan, seperti yang diungkapkan oleh Herson salah tokoh agama, yaitu pembacaan Barzanji, yang kedua yaitu pemotongan rambut, yang ketiga pembacaan doa selamat untuk anak tersebut. ${ }^{8}$

Bahan-bahan tersedia pada saat pelaksanaan ritual adat posalama ini yaitu kelapa, beras, uang, lilin, air satu gelas dan daun siranindi. Bahan-bahan ini bagi masyarakat etnis Kaili di Kelurahan Petobo terdapat arti masing-masing sebagai berikut:

a. Bahan didalam jaka (sebuah mankok kecil)

1) Ose puti (beras putih)

Makna dari beras putih adalah diharapkan anak yang akan di akikah mendapat rezeki yang banyak, tidak kelaparan (kesusahan), serta ketika hidup bermasyarakat selalu rendah hati.

2) Doi (uang)

${ }^{7}$ Sanaria. Tokoh adat perempuan Kelurahan Petobo. Wawancara oleh penulis di Huntara. 01 Februari 2021.

${ }^{8}$ Herson. Tokoh Agama Kelurahan Petobo. Wawancara oleh penulis dirumah. 01 Februari 2021 
Dalam pelaksanaan ritual adat posalama pogunci bulua terdapat bahan-bahan yang harus disiapkan diantaranya yaitu uang. Uang dalam ritual adat ini berkaitan dengan beras putih bermakna sebagai do'a agar anak mendapatkan limpahan rezeki dari Allah swt serta ketika mempunyai rezeki yang lebih dapat bersedekah dan membantu yang kesusahan. ${ }^{9}$ Beras dan uang yang ada didalam jaka tersebut kemudian disedekahkan kepada yang memandu acara atau yang menggunting rambut anak tersebut. ${ }^{10}$

3) Lili puti (lilin putih)

Dalam ritual adat ini lilin putih bermakna sebagai do'a agar anak tersebut memiliki masa depan yang cerah dan terang seperti terangnya cahaya api lilin. ${ }^{11}$

4) Ntalu (telur)

Telur yang ada didalam jaka (mankok kecil) ini bermakna agar anak nantinya ketika dewasa memiliki tekat yang bulat dalam melakukan suatu pekerjaan sebagaimana bentuk telur yang bulat. ${ }^{12}$

Makna dari bahan-bahan yang disediakan ketika ritual adat dilaksanakan pada dasarnya adalah sebagai do'a yang dipanjatkan kepada Allah Swt., hal ini merupakan suatu tradisi yang diwariskan oleh leluhur mereka, yang mana di zaman dahulu sebelum mengenal ajaran ataupun syariat agama islam, mereka belum mengetahui cara bagaimana memanjatkan do'a kepada Allah swt, sehingga doa atau permohonan mereka kepada Allah swt digambarkan lewat simbol-simbol yang tersedia. Maka makna dari jaka adalah sebuah do'a dan harapan yang dipanjatkan kepada Allah swt untuk kehidupan anak dalam menjalani hidupnya sehari-hari.

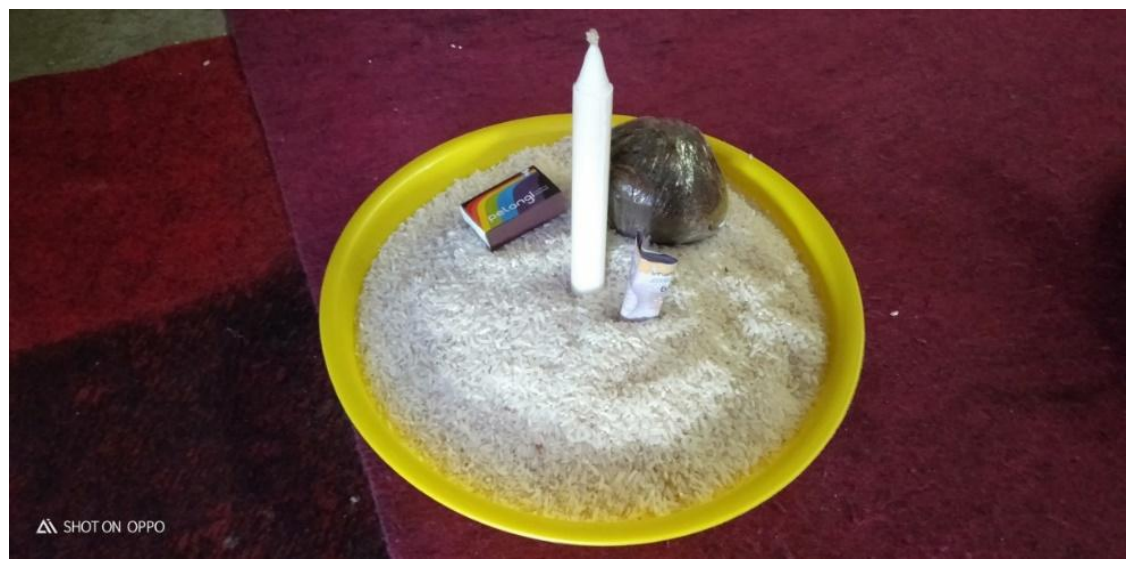

Gambar 2. Bahan didalam jaka

${ }^{9}$ Satar Yaburisa. Tokoh Masyarakat Kelurahan Petobo. Wawancara oleh penulis dirumah, 27 Januari 2021

${ }^{10}$ Suharto H. Maila. Tokoh masyarakat. Wawancara oleh penulis dirumah. 14 Februari 2021

${ }^{11}$ Sanaria. Tokoh adat perempuan Kelurahan Petobo. Wawancara oleh penulis di Huntara. 01 Februari 2021.

${ }^{12}$ Suardin Ilyas. Dewan Suro Kelurahan Petobo. Wawancara oleh penulis dirumah. 27 Januari 2021. 
b. Bahan yang ada pada loja (sebuah talang kecil)

1) Kaluku posalama (kelapa untuk selamatan)

Dalam pelaksanaan adat posalama pogunci bulua kelapa yang digunakan adalah kelapa muda yang warnanya kuning. Kelapa tersebut diambil dari pohonnya kemudian tidak dijatuhkan ke tanah akan tetapi dibawa langsung dari atas pohon. Pohon kelapa adalah tumbuhan yang memiliki banyak manfaat, dalam pelaksanaan ritual adat posalama pogunci bulua kelapa sebagai simbol agar anak ini dapat bermanfaat bagi keluarga dan masyarakat sekitarnya dan juga bermakna agar anak tersebut dapat beradaptasi dengan lingkungan yang ada, sehingga walaupun hidup ditengah orang yang berbeda suku, agama dan ras namun tetap mengutamakan sikap toleransi dalam keberagaman sebagaimana pohon kelapa yang dapat tumbuh dimana saja. ${ }^{13}$

2) Uve puti sangu kaca (air putih satu gelas)

Manusia dalam hidupnya sangat membutuhkan air, sehingga air sebagai salah satu sumber kehidupan bagi manusia. Air ini bermakna sebagai gambaran hidup yang kemudian menyatu dengan sifat manusia. Air pada ritual adat posalama pogunci bulua bermakna agar anak tersebut nantinya dalam menjalani hidupnya rezekinya dilancarkan seperti air yang mengalir. ${ }^{14}$

3) Colo (korek api)

Macis ini digunakan untuk membakar lilin yang ada pada ritual adat ini.

4) Gunci (gunting) akikah.

Gunting ini berfungsi untuk menggunting rambut si anak yang akan di

5) Tava siranindi (daun cocor bebek)

Menurut keyakinan etnis Kaili di Kelurahan Petobo bahwa daun siranindi ini adalah simbol dingin, maksudnya agar anak ini diberi kesehatan, tidak sakit dan tidak sering menangis. Seperti yang dikatakan oleh tokoh adat perempuan "daun siranindi ini adalah simbol do'a agar anak diberi kesehatan oleh Allah Swt."

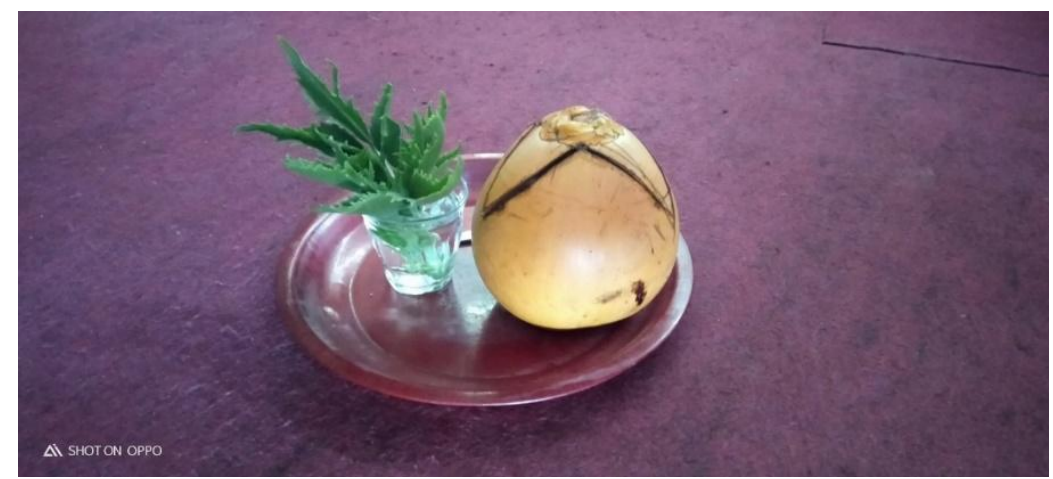

Gambar 3. Bahan didalam Loja

\footnotetext{
${ }^{13}$ Satar Yaburisa. Tokoh Masyarakat Kelurahan Petobo. Wawancara oleh penulis dirumah, 27 Januari 2021

${ }^{14}$ Suharto H. Maila. Tokoh masyarakat. Wawancara oleh penulis dirumah. 14 Februari 2021

${ }^{15}$ Sanaria. Tokoh adat perempuan Kelurahan Petobo. Wawancara oleh penulis di Huntara. 01 Februari 2021.
} 
Ritual adat posalama pogunci bulua adalah adat istiadat yang diwariskan oleh para leluhur mereka, karena pada zaman dahulu, mereka (leluhur) berdo'a meminta untuk diberi kesehatan, kelimpahan rezeki melalui simbol-simbol yang ada dan simbol yang digunakan berkaitan dengan keyakinan para leluhur mereka yang telah menjadikan tradisi ini sebagai suatu bagian penting dalam prosesi akikah. ${ }^{16}$ Sebagaimana yang diungkapkan oleh Clifford Geertz, ritual sebagai suatu sistem simbol yang berfungsi memantapkan perasaan-perasaan dan motivasi secara kuat, menyeluruh dan bertahan lama didalam diri manusia. Perasaan-perasaan itu dirumuskan dalam suatu sistem aturan atau hukum keteraturan (order), sehingga motivasi dan perasaan-perasaan tersebut menjadi nyata. Ritual juga dilihat sebagai bentuk tindakan yang berfungsi sebagai penghubung antara pemikiran manusia dengan suatu realitas yang adikodrati. Hal ini berarti ritual merupakan bagian kecil dari kebudayaan yang mana sebagai upaya ungkapan perasaan manusia-manusia yang berbudaya terhadap suatu kekuatan tertentu. Kekuatan itu bisa saja berasal dari Wujud Tertinggi dan disampaikan melalui alam semesta atau kosmos tempat manusia mengada. ${ }^{17}$

Selain dari pelaksanaan ritual adat posalama pogunci bulua dengan menggunakan bahan-bahan yang digunakan dalam prosesi ritual tersebut sebagai simbol atau pertanda bukan hanya menyampaikan gambaran tentang sesuatu yang bersifat inmaterial berupa do'a, rasa syukur dan pengharapan kepada yang maha pemberi, tetapi juga menyampaikan fenomena-fenomena material yang ada dalam hati dan pikiran. Dalam kaitan ini, simbol dapat dipahami sebagai ekspresi dalam wujud material yang digunakan masyarakat untuk menggambarkan sesuatu yang dipercaya. Senada dengan defenisi yang diungkapkan oleh Viktor Turner menjelaskan lebih lanjut bahwa tindakan religius manusia dapat tercermin melalui pemaknaan simbolik (yaitu segala hal yang berhubungan dengan arti sebuah benda, tindakan, peralatan maupun sesaji) dari perilaku ritual/upacara yang bersumber dari hal intim batiniah individu (iman) kemudian berevolusi menjadi sebuah ritus sosial. $^{18}$

Memperhatikan definisi diatas Ritual adat posalama pogunci bulua dalam prosesi akikah masyarakat etni kaili di kelurahan petobo sebuah tradisi bagian dari upaya ungkapan perasaan manusia-manusia yang berbudaya terhadap suatu kekuatan dengan kata lain etnis kaili meyakini bahwa Ritual adat posalama pogunci bulua adalah bagian dari ekspresi rasa syukur akan karunia Allah Swt dengan diberikan keturunan, selain itu juga mempererat tali seilaturrahmi antar keluarga tentangga dan masyarakat di daerah tersebut.

\section{Ritual adat posalama pogunci bulua dalam tinjauan pendidikan Islam}

Ritual adat posalama pogunci bulua yang dilaksanakan dalam prosesi akikah mulai dari awal hingga akhir ritual adat dilaksanakan merupakan do'a dan harapan yang disampaikan melalui simbol ataupun bahan-bahan yang digunakan.

\footnotetext{
${ }^{16}$ Abd. Naim. Tokoh masyarakat. Wawancara oleh penulis di Huntara, 05 Februari 2021

${ }^{17}$ Yosep Belen Keban Intepretasi Slametan (CV. Penerbit Qiara Media. 2019), 31

${ }^{18}$ Mariasusai Dhavamony, Fenomenologi Agama (Yogyakarta: Kanisius, 2010), 167
} 
Tahapan-tahapan pelaksanaan ritual adat posalama pogunci bulua terdapat nilai-nilai pendidikan Islam yang mencakup:

a. Nilai pendidikan keimanan.

Pendidikan keimanan adalah sinergi berbagai unsur aktifitas pedagogis, diantaranya: pengaitan anak dengan dasar-dasar keimanan, pengakraban dengan rukun Islam, dan pembelajaran tentang prinsip-prinsip syariat Islam. ${ }^{19}$ Dalam proses pelaksanaan ritual adat posalama pogunci bulua terdapat bahan-bahan yang disediakan dan pembacaan barzanji yang semuanya mengandung do'a untuk kebaikan sang anak. Nilai pendidikan keimanan dalam pelaksanaan adat posalama pogunci bulua yaitu tentang ajaran syariat agama islam. Masyarakat bisa mengambil pelajaran tentang akikah, antara lain pengertiannya, tata cara dan syarat-syaratnya serta hukum pelaksanaannya. ${ }^{20}$ Hal ini selaras dengan pengertian Pendidikan Islam menurut Achmadi sebagai segala usaha untuk memelihara dan mengembangkan fitrah manusia serta sumber daya manusia yang ada padanya menuju terbentuknya manusia seutuhnya (insan kamil) sesuai dengan moral Islam, yakni untuk membentuk manusia yang beriman dan bertakwa serta memiliki berbagai kemampuan yang teraktualisasi dalam hubungannya dengan Allah SWT, dengan sesama manusia dan alam sekitarnya $^{21}$

b. Nilai pendidikan akhlak

Pendidikan akhlak yaitu usaha yang dilakukan secara sadar untuk membimbing dan mengarahkan kehendak seseorang untuk mencapai tingkah laku yang mulia dan menjadikannya sebagai kebiasaan. Pendidikan merupakan usaha untuk membentuk manusia yang utuh lahir dan batin cerdas, sehat, dan berbudi pekerti luhur. ${ }^{22}$ Pelaksanaan adat posalama pogunci bulua terdapat beberapa nilai-nilai akhlak. Diantaranya yaitu pada saat pembacaan Mahallul Qiyam para tamu undangan diminta untuk berdiri untuk menghormati baginda Rasulullah Saw. ${ }^{23}$ Pada saat makan bersama ada nilai akhlak yang terkandung yaitu islam mengajarkan tentang adab makan harus duduk.

\footnotetext{
${ }^{19}$ Nurul Azizah, Nilai-nilai pendidikan Islam dalam hadis-hadis Akikah. Jurnal Pendidikan Agama Islam Universitas Wahid Hasyim Volume 7, No 1, Juni 2019, 88

${ }^{20}$ Adhitya Sukarno Widodo. Tokoh agama Kelurahan Petobo wawancara oleh penulis dirumah. 04 februari 2021

${ }^{21}$ Achmadi, Idiologi Pendidikan Islam; Paradigma Humanisme Teosentris, (Yogyakarta: Pustaka Belajar, 2005), h. 28-29

${ }^{22}$ Hamlan, Sjakir Lobud, \& M.A. Kadengkang. Implementasi nilai-nilai pendidikan islam terhadap adat mogama'pada masyarakat nuangan 1 kabupaten bolaang mongondow. Moderasi: Jurnal Studi IImu Pengetahuan Sosial, 1(1) 2020, 15-37.

${ }^{23}$ Adhitya Sukarno Widodo. Tokoh agama Kelurahan Petobo wawancara oleh penulis dirumah. 04 februari 2021
} 
c. Nilai pendidikan sosial.

Pendidikan sosial adalah proses pembinaan kesadaran sosial, sikap sosial, dan keterampilan sosial agar anak bisa hidup dengan baik ditengah-tengah masyarakat. ${ }^{24}$

Nilai sosial dalam pelaksanaan ritual adat posalama pogunci bulua diantaranya yaitu ketika sebelum pelaksanaan, tetangga dan sanak saudara datang membantu keluarga untuk pelaksanaan akikah, mereka membantu sesuai dengan keahliannya masing-masing, ada yang memotong daging, ada yang memasak nasi, ada yang memasak sayur dan ada juga yang bagian mencuci piring, mereka bertugas tanpa harus diperintah karena sudah memahami tugasnya sendiri-sendiri.

Ketika pelaksanaan akikah, mereka saling gotong royong nosijoko baki (mengangkat baki) yang berisi makanan, kemudian baki tersebut diberikan dari orang yang satu ke orang yang lain, yang membantu bukan hanya keluarga akan tetapi anak-anak remaja, mengajarkan mereka rasa saling tolong menolong. ketika mau menyantap makanan, mereka semua duduk bersama dalam satu baki (talang besar) itu tiga sampai empat orang. Ini adalah nilai sosial yang paling tinggi. Seperti yang diungkapkan oleh salah satu tokoh agama, sekaligus pengasuh pondok pesantren Al-Munadji di Kelurahan Petobo.

"Dengan duduk bersama saat makan diacara posalama pogunci bulua, dapat meningkatakan rasa ukhuwah, kebersamaan, walaupun berasal dari latar belakang pendidikan, pekerjaan dan status sosial yang berbeda-beda" 25

Pelaksanaan ritual adat posalama pogunci bulua di Kelurahan Petobo terdapat nilainilai pendidikan Islam yang mencakup nilai pendidikan keimanan, akhlak dan pendidikan sosial. Pada penelitian terdahulu oleh Nurul Azizah tentang nilai-nilai pendidikan Islam dalam hadis akikah termasuk didalamnya yaitu nilai pendidikan keimanan, akhlak dan sosial. Pendidikan keimanan dalam pelaksanaan akikah yaitu melalui pemberian do'a kepada anak yang dilakukan dengan mengundang sanak saudara dan tetangga. Dalam upacara tersebut semua tamu yang hadir ikut serta mendo'akan agar kelak menjadi pribadi yang baik. Pendidikan akhlak diantaranya yaitu men-tahnik atau memberi manis-manis di mulut bayi. Dengan men-tahnik diharapkan jika besar nanti anak bertutur kata yang manis-manis, berkata-kata yang sopan kepada yang lebih tua, tidak membuat orang tersinggung dan sakit hati jika mendengarnya. Pendidikan sosial diantaranya yaitu ketika rambut anak yang dicukur kemudian ditimbang lalu disedekahkan. Hal ini mengandung pendidikan sosial yang dapat mengurangi kemiskinan dan mewujudkan suasana saling menolong, saling menyayangi, dan saling menjamin dalam kelompok masyarakat. Hal tersebut akan memperkuat silaturrahim antara masyarakat. Maksud dari

\footnotetext{
${ }^{24}$ Bukhari Umar, Hadits Tarbawi Pendidikan dalam Perspektif Hadis, (Jakarta: Amzah, 2012): 55

${ }^{25}$ Adhitya Sukarno Widodo. Tokoh agama Kelurahan Petobo wawancara oleh penulis dirumah. 04 februari 2021
} 
mempererat dari silaturrahim yaitu menguatkan ikatan keakraban dan kecintaan antara sesama anggota masyarakat karena berkumpulnya mereka dihadapan hidangan yang sudah disediakan artinya bergembira dalam menyambut anak yang baru lahir. ${ }^{26}$

Sebagaimana Khoiron Rosyadi mengungkapkan bahwa Pendidikan adalah usaha pembinaan dan pengembangan potensi manusia secara optimal sesuai dengan statusnya, dengan berpedoman kepada syariat Islam yang disampaikan oleh Rasul Allah yang setia dengan segala aktivitasnya guna tercipta suatu kondisi kehidupan Islam yang ideal, selamat, aman, sejahtera dan berkualitas serta memperoleh jaminan (kesejahteraan) hidup di dunia dan jaminan bagi kehidupan yang baik diakhirat ${ }^{27}$. Merujuk pada pengertian tersebut Pelaksanaan adat posalama pogunci bulua sebagai wadah dalam menginternalisasikan nilai Pendidikan Sosial sesuai dengan nilai-nilai Pendidikan islam.

\section{Simpulan}

Proses pelaksanaan ritual adat posalama pogunci bulua pada etnis Kaili di Kelurahan Petobo mempunyai beberapa tahapan-tahapan yang harus dilaksanakan diantaranya yaitu adat pokeso, menyiapkan bahan-bahan yang digunakan pada saat ritual adat dilaksanakan dan acara akikah. Dalam pelaksanaan ritual adat ini mereka masih menggunakan tradisi-tradisi yang diwarisi oleh leluhur mereka yaitu dengan menggunakan simbol-simbol seperti kelapa, beras, lilin, daun siranindi, telur dan uang. Simbol-simbol tersebut memiliki makna-makna tersendiri. Bagi masyarakat etnis Kaili di Kelurahan Petobo bahwa ritual adat posalama pogunci bulua ini adalah salah satu bentuk rasa syukur kepada Allah Swt. atas anak yang dititipkan kepada mereka dan juga sebagai tempat silaturahim antar keluarga dan tetangga. Sedangkan makna yang terkandung pada simbol-simbol yang digunakan bukanlah sebagai bahan untuk disembah melainkan sebagai do'a dan harapan kedua orang tua kepada anak tersebut yang mereka panjatkan kepada Allah Swt.

Dalam tinjauan pendidikan Islam, ritual adat posalama pogunci bulua ini mengandung nilai-nilai pendidikan diantaranya yaitu nilai pendidikan keimanan, nilai pendidikan akhlak dan nilai pendidikan sosial.

\footnotetext{
${ }^{26}$ Nurul Azizah, Nilai-nilai pendidikan Islam dalam hadis-hadis Akikah. Jurnal Pendidikan Agama Islam Universitas Wahid Hasyim Volume 7, No 1, Juni 2019, 94-96

${ }^{27}$ Khoiron Rosyadi, Pendidikan Profetik, (Yogyakarta: Pustaka Belajar, 2004), h.135
} 


\section{DAFTAR PUSTAKA}

Achmadi, Idiologi Pendidikan Islam; Paradigma Humanisme Teosentris, (Yogyakarta: Pustaka Belajar, 2005),

Imran Arbi Pogogul dan Orang Buol (Mitos Kepercayaan Orang Buol terhadap Kesakralan Gunung Pogogul di Desa Taluan Kecamatan Momunu Kabupaten Buol. 2006)

Henri, Tradisi Akcaru-caru dalam pelaksanaan di Desa Sala’jangki Kecamatan Bontonompo Selatan Kabupaten Gowa (Studi Dakwah Kultural) Skripsi diterbitkan (Makassar: Jurusan Komunikasi dan Penyiaran Islam, UIN Alauddin)

Sofyan A.P. Kau Islam dan Budaya Lokal Adat Gorontalo (makna filosofis, Normatif, Edukatif dan Gender (Malang : PT Cita Intrans Selaras, 2020)

Sugiyono, Metode Penelitian Pendidikan Pendekatan Kuantitatif, Kualitatif dan RED, (Bandung: Alfabet, 2010)

Yosep Belen Keban Intepretasi Slametan (CV. Penerbit Qiara Media. 2019) Mariasusai Dhavamony, Fenomenologi Agama (Yogyakarta: Kanisius, 2010) Moh. Rifa'I Fiqih Islam lengkap (Semarang : PT. Karya Toha Putra Semarang, 2014) Nurul Azizah, Nilai-nilai pendidikan Islam dalam hadis-hadis Akikah. Jurnal Pendidikan Agama Islam Universitas Wahid Hasyim Volume 7, No 1, Juni 2019

Bukhari Umar, Hadits Tarbawi Pendidikan dalam Perspektif Hadis, (Jakarta: Amzah, 2012)

Malla, H. A. B., Lobud, S., \& Kadengkang, M. A. (2020). IMPLEMENTASI NILAINILAI PENDIDIKAN ISLAM TERHADAP ADAT MOGAMA'PADA MASYARAKAT NUANGAN 1 KABUPATEN BOLAANG MONGONDOW. Moderasi: Jurnal Studi Ilmu Pengetahuan Sosial, 1(1) DOI: https://doi.org/10.24239/moderasi.Vol1.Iss1.7

Khoiron Rosyadi, Pendidikan Profetik, (Yogyakarta: Pustaka Belajar, 2004)

WAWANCARA

Halati Yabudjira. Ketua Adat Kelurahan Petobo, Wawancara oleh penulis dirumah Ketua Adat. 26 Januari 2021.

Suardin Ilyas. Dewan Syuro Kelurahan Petobo. Wawancara oleh penulis dirumah. 27 Januari 2021.

Sanaria. Tokoh adat perempuan Kelurahan Petobo. Wawancara oleh penulis di Huntara. o1 Februari 2021.

Herson. Tokoh Agama Kelurahan Petobo. Wawancara oleh penulis dirumah. o1 Februari 2021

Satar Yaburisa. Tokoh Masyarakat Kelurahan Petobo. Wawancara oleh penulis dirumah, 27 Januari 2021

Suharto H. Maila. Tokoh masyarakat. Wawancara oleh penulis dirumah. 14 Februari 2021

Sanaria. Tokoh adat perempuan Kelurahan Petobo. Wawancara oleh penulis di Huntara. o1 Februari 2021. 
Suardin Ilyas. Dewan Suro Kelurahan Petobo. Wawancara oleh penulis dirumah. 27 Januari 2021.

Satar Yaburisa. Tokoh Masyarakat Kelurahan Petobo. Wawancara oleh penulis dirumah, 27 Januari 2021

Suharto H. Maila. Tokoh masyarakat. Wawancara oleh penulis dirumah. 14 Februari 2021

Sanaria. Tokoh adat perempuan Kelurahan Petobo. Wawancara oleh penulis di Huntara. o1 Februari 2021.

Abd. Naim. Tokoh masyarakat. Wawancara oleh penulis di Huntara, o5 Februari 2021 Adhitya Sukarno Widodo. Tokoh agama Kelurahan Petobo wawancara oleh penulis dirumah. 04 februari 2021

Adhitya Sukarno Widodo. Tokoh agama Kelurahan Petobo wawancara oleh penulis dirumah. 04 februari 2021 